\title{
8. HISTORICAL POLICY REVIEW ON DISABILITY
}

- Ramesh Baral ${ }^{8}$

\begin{abstract}
Historical Policy Review on disability is a comprehensive historical policy analysis of past, barriers, and developing trend and disability in Nepal. People with disability in Nepal seems to be suffering from different dimensions. The article is focused on history and policy led aspects in Nepal. Are the policies sufficient? This article seeks to objectively identify the policy gaps and historical development of institutional support for people with disability in Nepal. Methodologically, the article is a descriptive analysis of disability in Nepal. The article has adopted internet based library method to review the policy gaps and history of development trend of support for people with disability. In conclusion, it is obvious from the review of policies and international conventional commitments that Nepal has sufficient policies regarding the people with disability. The most serious issue is good governance of organizations. Lack of responsibility, accountability and transparency are still a problem though there are many policies emphasizing the solutions to these problems. This means the implementation aspects of disability are very disappointing. Historically, mythological, and cultural aspects of disability are not defined scientifically. Therefore, the same problems anomalies are seen in contemporary lives of people with disability.
\end{abstract}

Keywords: Disability, Historical Policy Review

\section{Introduction}

For a long time, disability in Nepal has primarily been a family concern and occasionally it has received some focus from public charity (in bigger urban centers like Kathmandu) and private philanthropy (in and around popular religious locations) (Banskota, 2015). Within a family also it is still a common practice to use the stigmatizing tag of "disfavor" with disabled conditions of family members and most of the families in Nepal still consider disability as a punishment for all the depravities and wickedness disable persons have committed in their past lives. Besides, the burden of disability is mostly put on the mothers of disabled child (Banskota, 2015). The estimation of WHO is that the percentage of disabled people in developing countries is around $15 \%$. There are approximately 650 million people living with disabilities worldwide and an estimated 200 million of these are children. $80 \%$ of disabled people reside in low- and middleincome countries, and the number continues to increase (WHO, 2011). The different agencies unanimously identified five characteristics of access to health care:

- Availability - the type and extent of services

- Accessibility - physical barriers relative to location

8 Mr. Baral is a PhD scholar at TU and involved in the field of PWD. 
Research Nepal Journal of Development Studies (Volume I Issue 1, 2018 May)

- Accommodation - sensitivity to individual differences or functioning

- Affordability - financial, time or energy costs

- Acceptability - mutual acceptance and reciprocity.

While many people do access and receive good health care, equity of access for some groups, particularly people with disabilities, can be problematic and this has been recognized by some service providers specifically in the area of physical and staff attitudinal barriers.

Theoretically, citing Neuman (2000), (Creswell, 2009) reviews theories at three levels: micro-level, meso-level, and macro-level. Micro-level theories provide explanations limited to small slices of time, space, or numbers of people, such as Goffman's theory of face work, which explains how people engage in rituals during face-to-face interactions. Meso-level theories link the micro and macro levels. These are theories of organizations, social movement, or communities, such as Collins's theory of control in organizations. Macro-level theories explain larger aggregates, such as social institutions, cultural systems, and whole societies. Lenski's macro-level theory of social stratification, for example, explains how the amount of surplus a society produces increases with the development of the society (Creswell, 2009).

Critical disability theory centers disability as it compares liberalism's norms and values with their actualization in the daily life of disabled people. It outlines seven elements of CDT: the social model of disability; multidimensionality; valuing diversity; rights; voices of disability; language; and transformative politics. Critical disability theory (CDT) is an emerging theoretical framework for the study and analysis of disability issues (Hosking, 2008).

Since it was first proposed by Max Horkheimer in 1937, critical theory has come to include a wide range of descriptive and normative bases for social inquiry which have the practical aim of maximizing human freedom and ending the domination of some groups by others defined by class, power, race or other social construct (Hosking, 2008). Unlike traditional theory, critical theory makes no claim to be normatively objective - its purpose is to explain oppression and to transform society with the objective of human emancipation. Despite the extensive variation in the critical theory tradition, any adequate critical theory must be explanatory, practical, and normative, all at the same time. That is, it must explain what is wrong with current social reality, identify the actors to change it, and provide both clear norms for criticism and achievable practical goals for social transformation. CDT, as a member of the critical theory family, is a theoretical approach to the concept of disability which is simultaneously explanatory, practical and normative (Hosking, 2008)

A theory which centers disability and proceeds from the perspective of disabled people needs to have a conception of disability which is sufficiently inclusive to encompass the population with which it is concerned. What this conception should be and how any definition can avoid being over- or under-inclusive is a key concern of critical disability theory (Hosking, 2008). In my 
view, a 'universalist' conception of disability, which proposes that everyone may be placed on a continuum from disabled to not disabled and argues that disability is universal since everyone is disabled at some time in their lives, is an insufficient basis upon which to analyses the social condition of disabled people and develop social policy which is responsive to the interests of this very diverse population (Creswell, 2009). This necessitates some, inevitability contested, conception of disability which reasonably identifies the population in question without lapsing into essentialism. Broadly stated, liberalism has traditionally conceived of disability as personal misfortune preferably to be prevented and definitely to be cured, privileges 'normalcy' over the 'abnormal', presumes able-bodied norms are inevitable, and values economic productivity as an essential aspect of personhood (Hosking, 2008).

In the early days of the social model disabled activists often made the extreme claim that no impairment was disabling: Only the failure of society to accommodate difference limited an individual's life options. This conception of the social model met the needs of the times - a mighty shove is needed to overcome inertia and without this extreme proposition the medical model may never have been budged. But now the social model is widely accepted and, while recognizing the need to avoid reverting to an essentialist conception of disability, a complete account of disability must incorporate the personal experience of impairment and illness. The CDT version of the social model is the synthesis of the medical and social models which the World Health Organization calls the "biopsychosocial model (Hosking, 2008). This approach balances the contributions of impairment, personal responses to impairment and the barriers imposed by the social environment to the concept of disability.

Public policy must respond to both the biomedical and social aspects of disability. Prevention, treatment and rehabilitation are all appropriate responses to the biomedical, or impairment, aspects of disability. For those people who continue to experience social marginalization despite interventions responding to their biomedical circumstances, the appropriate policy response is to change the social environment. There is, however, an inherent dialectical tension between the medical model which seeks to abolish disabling impairments and a social model which accepts and truly values disabled people as equal, integrated members of society (Creswell, 2009). Critical disability theory probes this tension by questioning, among other things, concepts of personal independence and interdependence, the social construction of 'nondisability' as well as disability, the concept of normalcy, fundamental values of individual dignity and respect in democratic societies, and issues at the intersection of disability with class, gender, race, sexual orientation, ethnicity and other socially constructed categories (Creswell, 2009).

Critical disability theory adopts a version of the social model based on the principles that (1) disability is a social construct, not the inevitable consequence of impairment, (2) disability is best characterized as a complex interrelationship between impairment, individual response to impairment, and the social environment, and (3) the social disadvantage experienced by disabled people is caused by the physical, institutional and attitudinal (together, the 'social') environment which fails to meet the needs of people who do not match the social expectation of 'normalcy 
(Hosking, 2008). The study incorporates 1. Critical Disability Theory 2. Goffman's Theory of face work, 3. Lanski's Macro level theory of social stratification and 4. Collins theory of control in organizations in meso level.

\section{Typology}

For the purposes of distributing disability identity cards, the GON has classified disability, on the basis of its level of severity, as follows:

(a) Profound disability: Difficulty to perform daily activities even with the help of others.

(b) Severe disability: Inability to perform daily individual or social activities without the help of others.

(c) Moderate disability: Ability to perform daily activities and participate in social life if barrier free environment, appropriate training and education are provided.

(d) Mild disability: Ability to perform daily activities and participate in social life if barrier free environment is provided. (Banskota, 2015)

Above provisions are considered as the basic elements for ensuring human rights of persons with disability, as well as for their social inclusion, respectable rehabilitation and expansion of services. Here, an argument can be made that the current situation of PWDs will significantly improve with the successful implementation of these proposed measures (Banskota, 2015). Government of Nepal has reclassified the type of disability into 7 categories in 2007. 1) Physically disabled, 2) Visually impaired, 3) Deaf, 4) Deaf Blind, 5) Speech and hearing disability, 6) Mental disability, 7) Multiple.

\section{Methodology}

The article is to identify the policy gaps and historical development of institutionalized assistance for people with disability in Nepal. Methodologically the study is a descriptive analysis of the disability in Nepal. The article has adopted internet based library method to find out the policy gaps and history of development trend of assistantship on disability.

\section{Analysis / Discussion}

\section{a) Historical Reviews}

Declaration of the International Year of Disabled Persons (IYDP) 1981 under the theme "Full Participation and Equality" taken by the UN General Assembly was an important breakthrough in the field of disability (Joshi, 2004). It was strongly urged that the UN system should make all facilities totally barrier-free, and encourage equality and full participation of disabled persons in all activities of the society. All the member states were requested to form National Committees 
or similar coordination bodies to deal with the problem of disability. As a follow-up program of IYDP, the years 1983-1992 was declared The UN Decade of Disabled Persons (Joshi, 2004).

From Nepalese perspective substantial change in the perception of Nepali society towards disabled persons took place in 1977 after the formation of the Social Service National Coordination Council that was headed by Queen Aishwarya Shah. It was followed by several important changes like establishment of the Ministry for Social Welfare, the enactment of legislation for the Rights and Welfare of the Disabled, establishment of Social Welfare Council etc. (Joshi, 2004). In Nepal, since 1992, every year December 3rd is celebrated as International Day of the Disabled persons with various programs like procession of disabled persons, talk programs, workshops, seminars etc.

In the following year of International Year of Disabled Persons as proclaimed by the United Nations in 1981, Nepal enacted the Disabled Protection and Welfare Act, 1982 (the "DPW Act") National Policy and Plan of Action on Disability. Moreover, it was only after 1992, almost ten years later, the series of different legislations started to emerge such as the Education Act of 1992, Child Rights Acts of 1992 and Local Self-Government Act 1999 that have indirectly helped to bring forward PWD conditions closer to the policy makers.

In 1994, the Disabled Protection and Welfare Regulation (the "DPW Regulation") was framed to implement the DPW Act. Nepal signed the Convention on the Rights of Persons with Disabilities (the "CRPD") and the Optional Protocol to the Convention on the Rights of Persons with Disabilities (the "Optional Protocol") on $3^{\text {rd }}$ January 2008, and also ratified them on $27^{\text {th }}$ December 2009 (Banskota, 2015). The Constitution of Nepal, 2015 (the "Constitution") guarantees human rights and fundamental freedom to all its citizens. Hence, different measures have been coming into its strength for Nepal on $6^{\text {th }}$ June 2010. However, the important changes have been only initiated after 2006, following the decade long conflict that has forced Nepal to provide political high priority to social inclusion and human rights, including those of PWDs (Banskota, 2015).

\section{b) Policy Review}

\section{i. The International Context}

In 1975 the UN produced its Declaration of Rights for Disabled People followed in 1982 by the World Program of Action Concerning Disabled People being adopted by the General Assembly. In terms of education a United Nations world conference on Education for All meeting basic learning need was held in Jomtien, Thailand in 1990 followed by a world conference on Special Needs Education: access and quality in Salamanca, Spain in 1994 which produced the Salamanca Statement and Framework for Action (Banskota, 2015). The discussions arising out of these conferences and the publications produced as a result of them have, as we will see below, had an impact on educational policy and practice in Nepal. 1982-92 was declared the UN Decade of Disabled People and, at the end of this decade the United Nations Standard Rules on the Equalization of Opportunities for Persons with Disabilities was produced which provided a basis 
for international co-operation and an instrument for policy-making and actions for people with disabilities (WHO, 2011). However, these rules have no formal, binding authority. In 1997 the Dhaka Declaration stated that all Governmental and non-Governmental organizations working in this region recognize that handicap and disability are development issues. 2003-12 has been stated as being the Asian and Pacific Decade of Disabled Persons and, in response to this, the UN ESCAP has produced the Biwako Millennium Framework for Action: towards an Inclusive, Barrier-free and Rights-based Society for Persons with Disabilities in Asia and the Pacific.

\section{ii. The Nepali Legal Context}

The first legislation related specifically to disabled people in Nepal was the Disabled Persons (Protection and Welfare) Act (1982). However, the Rules to lay down how this legislation might be exercised were not produced for another twelve years in 1994 (Banskota, 2015). The newly adopted Constitution of Nepal, 2072 (September, 2015), in its article 31, clearly declared that every person with disability shall have the right to free education up to the higher-secondary level. Similarly, it is also clearly stated that persons with visual disability shall have access to Braille and persons with deaf and hard of hearing disability to sign language (Eide, Neupane, \& Hem, 2016). The Act contains the following provisions:

Education:

a. No fees shall be charged to disabled students.

b. $5 \%$ of places in Government organizations providing vocational training should be reserved for disabled people.

c. NGOs or private organizations that provide education and training for disabled people can ask for assistance from the Government.

d. A Disabled Relief Fund (established in 1981) can allocate scholarships to disabled students (Joshi, 2004).

Health:

a. Disabled people are entitled to free medical examination.

b. All hospitals with more than 50 beds should allocate two beds for the use of disabled people.

c. There should be free treatment for disabled people over the age of 65 (Joshi, 2004). 
Employment:

It is prohibited to discriminate against disabled people in relation to employment. Individual businesses employing more than 25 people should give $5 \%$ of their jobs to disabled people. There should be income tax exemption for employers who employ disabled people. There should be no duties on specialist equipment required by disabled employees. $5 \%$ of jobs in the Civil Service should be allocated to disabled people (Banskota, 2015).

Self-employment:

The Act directs the Government to provide programs which support disabled people into selfemployment. It also states that the Disabled Relief Fund should allocate loans of between 5,000/and 20,000/- in order for them to establish themselves as self-employed (Banskota, 2015).

Transport:

The Act allows for transport companies to allow disabled people to travel at half the regular fare but this can only be undertaken with the agreement of the particular company. At the present time, all transport in Nepal is privately owned (Joshi, 2004).

Social Welfare:

The Act allows for disability allowance to be paid to disabled people, but this is a power rather than a duty and is qualified by statement that this is subject to available resources.

People with mental health difficulties:

The Act states that people with a mental disorder should have arrangements made for them to be treated either at a hospital or at home. It also says that no disabled persons suffering from mental disease, save those against whom proceedings are being taken or who have been punished in a criminal offence under the prevailing law, shall not be kept in jail. Although this is then qualified by the next phrase except for treatment or security arrangements. Additional legislation in Nepal, The Education Act 2000 authorizes the Government to develop special rules for disabled people in education (Joshi, 2004).

The Social Welfare Act 1992 established the Social Welfare Council and gave the Government powers to develop special programs for disabled people. The Child Protection Act 1992, which was introduced to address issues raised in the UN Convention on the Rights of the Child, states that disabled children cannot be discriminated against and gives a duty that disabled children who cannot be cared for by their family must be provided for in children homes and receive necessary education (Joshi, 2004).

Recently New act entitled disability act 2017 has been passed by the parliament of Nepal. States Parties reaffirm that persons with disabilities have the right to recognition everywhere as persons 
before the law. States Parties shall recognize that persons with disabilities enjoy legal capacity on an equal basis with others in all aspects of life. States Parties shall take appropriate measures to provide access by persons with disabilities to the support they may require in exercising their legal capacity. States Parties shall ensure that all measures that relate to the exercise of legal capacity provide for appropriate and effective safeguards to prevent abuse in accordance with international human rights law. Such safeguards shall ensure that measures relating to the exercise of legal capacity respect the rights, will and preferences of the person, are free of conflict of interest and undue influence, are proportional and tailored to the person's circumstances, apply for the shortest time possible and are subject to regular review by a competent, independent and impartial authority or judicial body (United Nations, 2011).

The availability and accessibility of the data is a major instrument to address the issues of person with disabilities and for policy formation and program implementation. At national level, very few studies have been done in this sector, and those which are done have been limited to head count or prevalence rates only. However, still the estimate of disability in Nepal is found varying from one study to another. According to the latest population census carried out in 2011, the prevalence of disability is $1.94 \%$ in Nepal (Eide, Neupane, \& Hem, 2016).

\section{Findings}

Economically there are differences in economic activity to the advantage of control households. The large majority of both individuals with and without disability do not have work that gives them regular income. Results on economic activity, however, show clearly that control individuals and households are more integrated into the formal labor market. This must be regarded as the major reason for the economic/SES differences between the two groups (HHs and individuals), and the difference between the groups is exacerbated by the difference in mean number of household members in that case households cater for more people (Eide, Neupane, \& Hem, 2016).

Sociologically, the results reveal that many individuals with disability are excluded from the education system, and other indicators indicate lower school achievement among individuals with disability. Supported by the results of the study, the combination of many individuals with disability not accessing school and relatively small differences between school going cases and controls, indicates a Living Conditions. Study in Nepal selection processes whereby the most competent individuals with disability are included and the more severely disabled are excluded from education. This is thus a matter of both ensuring access to education for all and to improve the way students with disability are handled. While this study does not reveal the mechanisms whereby individuals with disability are excluded from their right to education, both competence and attitudes within the school system should be targeted to improve the situation (Eide, Neupane, \& Hem, 2016)

\section{From social inclusion:}

The results clearly indicate the inclusion as an area in need of intervention both at family/ 
household and community level. It adds to this that awareness of DPOs and membership in DPOs among individuals with disability is low, leaving the large majority of individuals with disability without this potentially important source of support (Eide, Neupane, \& Hem, 2016).

Unlike many other countries that have been included in similar research, there appears to be a substantial gap in access to health services among individuals with disability, with more than $40 \%$ stating that they did not receive health services even though they needed it. On one hand, this is the service with the smallest gap among the services included in the study. On the other hand, the gap is very high for such a critical service and simply implies that health coverage can hardly be said to be universal in this population. Gaps in services are very high for many of the services included, and simply indicate that many of the basic services are not available for large proportions of the disabled population and that the current specter of basic services is not sufficient to cater for the needs of individuals with disability.

This must be assumed to impact on the inclusion of individuals with disability in society and an evident area for improvements. This may partly be a capacity problem and partly a matter of exclusion. Further research will be necessary to reveal this. As these questions were not presented to non-disabled, we do not know to what extent access is lower among individuals with disability (Eide, Neupane, \& Hem, 2016). Individuals with disability have higher levels of anxiety and depression than non-disabled, and they rate both their physical and mental health lower. This is of importance as the status of being disabled may easily shadow for health problems. It is a prerequisite for equitable health services that service providers are conscious about the double burden of many individuals with disability, i.e. poorer mental and physical health in addition to the impairment/disability (Eide, Neupane, \& Hem, 2016).

Slightly more females reported experience of being discriminated in any public service than males, but the main impression is that gender differences are small. Any experiences of being beaten, scolded or discriminated are unacceptable and a violation of human rights, and it may be of some concern that violence/abuse by family members is reported by one in four in spite of the context of this data collection that one can assume contributed to underestimate the phenomenon. The results indicate that many individuals with disability suffer under unacceptable treatment in particular in their home environment (Eide, Neupane, \& Hem, 2016).

\section{Conclusion}

In conclusion, from the review of policies and international conventional commitments, Nepal has sufficient policies regarding the people with disability. The most serious issue is good governance of organizations. Lack of responsibility, accountability and transparency those policies are in shadowed area. It means implementation parts are very disappointing. It needs another study to check the issue from good governance perspective. On the other hand, development trends seem satisfactory. Historically, mythological, and cultural aspects on disability are not defined scientifically, so the same traditional impacts are seen in contemporary lives of people with disability. 


\section{References}

Banskota, M. (2015). Nepal Disability Policy Review. Kathmandu: School of Arts, KU, Disability Research Center.

Creswell, J. W. (2009). Research design: Qualitative, quantitative, and mixed methods approaches. New Delhi: Sage Publications.

Eide, A. H., Neupane, S., \& Hem, K.-G. (2016). Living Condition among Individuals with Disabilities in Nepal. Kathmandu : SINTEF Technology and Society, Department of Health Research .

Hosking, D. L. (2008). Critical disability theory. A paper presented at the 4th Biennial Disability Studies Conference, Lancaster University, UK:

Joshi, S. K. (2004). Disability in Nepal. KU Medical Journal (Voll. 2), 1-5.

United Nations (2011). Convention on the rights of persons with disabilities and optional protocal. Geneva: United Nations.

WHO (2011). World report on disability 2011. 20 Avenue Appia, 1211 Geneva 27, Switzerland: WHO Press, World Health Organization, . 